\title{
Management of Rockburst Risk at Falconbridge's Craig and Onaping Mines
}

\author{
B.P. Simser Falconbridge Sudbury Operations, Craig Mine, Canada
}

Rock bursts continue to be a major risk associated with high stress mining, particularly in hard, brittle rocks. At Falconbridges' Craig and Onaping Nickel Mines incidences of both strain bursting and more violent rock bursting occur erratically and with low predictability. Advances in yielding support systems have given rock mechanics engineers' tools to combat the problem more effectively; however intense ground support is expensive. Given the high potential for injury during a rockburst, and the small number of actual occurrences, the onus is often on the mines' rock mechanics program to select higher risk areas for burst resistant support, while maintaining a less expensive conventional support system for the majority of the mine. Several bursts are briefly described along with the implication for future mining at Craig/Onaping. Seismic monitoring, numerical modelling, and geotechnical drilling are used in conjunction with geological information to evaluate rockburst potential in different areas in the mining complex. Several case histories are used to show how the above tools can and are being used to guide mining sequences and support strategies. Changes in mining methods to reduce worker exposure in addition to adherence to good rock mechanics sequencing are the main risk mitigation methods. However rockburst resistant support packages are still prudent, particularly in the mines' faulted areas. Examples of the current yielding support implementation and planned strategies for future deeper mining are presented.

\section{INTRODUCTION}

Falconbridges' Craig and Onaping Mines are located in the northwestern flank of the Sudbury basin where nickel-copper ore is exploited up to $1700 \mathrm{~m}$ below surface. Both mines have mineral resources extending below existing workings and the stress regime is typical of many Canadian Mines where the maximum principal stress is sub-horizontal and approximately doubles the stress due to overburden (vertical component). Both mines use the Craig shaft system for men and material and are connected via ramp and lateral drives.

The Onaping Mine is extensively mined out above $1600 \mathrm{~m}$ below surface; current mining is incrementally extending to depth at a mining rate of approximately 500 tonnes per day. The mining methods are blasthole open stoping, with some post pillar cut and fill. The shaft system extends down to $1220 \mathrm{~m}$ below surface whereas active mining is from about $1600 \mathrm{~m}$ to $1740 \mathrm{~m}$. Ore and development waste are trucked via ramp to the more modern Craig Shaft system over a $4 \mathrm{~km}$ haulage distance. Material handling can be a significant bottle neck and limits some of the possible support options such as extensive shotcrete due to costs.

Three-dimensional inelastic modelling (3DEC) was used to evaluate risk in a highly stressed sill pillar recovery (O'Connor et al., 2004). The stope sequence and drill access location as well as some of the ground support strategy was selected based on the model results combined with local mining considerations. Yielding cables (Strandlok) and bolts (modified conebolts) were used in higher risk areas and some underground results are briefly summarized.

The Craig Mine extracts approximately 2200 tonnes per day using a combination of post pillar cut and fill mining $(\sim 60 \%$ of production) and blasthole open stoping. Occasionally drift and fill mining is used, for example coming under wider ore pods beneath sill mats. The current deepest mining zone (10-zone) is about $1500 \mathrm{~m}$ below surface and is traversed by a major fault system with three major faults and numerous splays and associated structures. Two major rock bursts occurred in April 2003 associated with fault-slip and large magnitude seismic events. The local mining was halted until a new operating plan could be developed. Geotechnical drilling was used to help evaluate risk in the 10-zone and the depth extension (11-zone). The mining methods and ground support strategies were also revised based on the fault zone location and geotechnical considerations.

An example of a sill pillar recovery (9505) is also used to show the effect of mining geometry, rock type, and mine sequencing on rock mechanics risk. The massive sulphide ore at Craig/Onaping has a much softer behaviour relative to the stiffer granitic footwall rocks. In addition wider, highgrade portions of the orebody "handle" higher stresses much better than narrower, low grade ore lenses (stiffer rock). Microseismic data is used to highlight the different risks.

\section{INFLUENCE OF GEOLOGY}

Generally speaking the footwall country rock at Craig/ Onaping is much more burst prone than the ore zones or hangingwall rocks. The footwall rock sequence (felsic gneisses, pink granites) is fine grained with relatively high unconfined compressive strengths (Table 1). Local variations in rockmass strength exist due to the degree of jointing and other geological structures. More "intact" areas are often a higher rockburst risk due to the stiffer overall response. Strain bursting is relatively common and can occur in development far from the influence of stoping.

The ore zones can be differentiated between low and high grade in terms of their rockburst risk. Craig/Onaping high grade massive sulphides are typically coarsely grained, well jointed (normally three joint sets) and softer than the footwall country rock. Stress fracturing is commonly observed but relatively few seismic events are recorded within the high grade ore itself ( >2\% nickel). Local strain energy build-ups are rare, with a more "plastic" response occurring relative to the country rock. Low grade ore is often disseminated nickel bearing sulphide material in a granitic matrix (Sudbury Breccia) with an overall stiffer response and higher rockmass strengths. 
Locally named "PYHF boulders" (pyroxene hornfel inclusions) are fined grained mafic fragments which vary in size between small, hand sized pieces to large open stope sized blocks. These are among the stiffest rocks in the mine and can cause local strain energy build-ups which have caused both strain and rock bursting. Low grade ore zones often have a high PYHF content brecciated within the ore.

There is limited hangingwall development at Craig/Onaping but the norite sequence of rocks is typically very blocky and not as prone to violent ejection type bursting. The unconfined compressive strength is relatively high, but the jointed nature of the rock has enough degrees of freedom to promote slip on weakness planes rather than strain energy accumulation.

Geological structure has historically been the biggest factor for major rockbursting at the mine. Relatively large fault systems (planar extents of hundreds of square metres) have been known to generate seismic events in the Nutli Magnitude 3 range ( Richter Magnitude 2.5). These larger events occasionally act as a trigger for local strain energy accumulations, which are released as the seismic wave passes through. The large magnitude events are felt on surface from depths of a kilometre or more but have a poor correlation to damage. Proximity to the epicentre, and local rockmass conditions govern the amount of damage observed. There are also a series of dykes traversing the mine. Rockmass strengths vary considerably but generally towards poor quality, with some dykes requiring extensive spiling and shotcrete to develop through. Fault-like movement at dyke contacts has been observed, and some dykes have been the source of large magnitude seismicity.

TABLE 1 Generic rock strengths for Craig/Onaping Mines. GSI = geological strength index (Hoek 2000), UCS = unconfined compressive strength in $\mathrm{MPa}$

\begin{tabular}{lll}
\hline Rock type & GSI & UCS \\
\hline High grade ore & 48 & 115 \\
Low grade ore & 65 & 174 \\
Felsic Gneiss & 80 & 250 \\
Dark Norite & 65 & 160 \\
Granite Breccia & 75 & 206 \\
\hline
\end{tabular}

Local jointing has a large influence on rock strengths, with some areas having weak, chloritic joints elevating the fall of ground hazard, and other areas having relatively few joints in stiff brittle rock (more burst prone). Table 1 above indicates generic geological strength indices (Hoek 2000) with most rock types lying in the blocky to very blocky categories with poor to good surface character.

\section{ROCKBURST MITIGATION MEASURES}

Where possible, good rock mechanics sequencing is promoted to avoid excessive stress accumulation, for example by designing pillars to fail or avoid leaving them (see 9505 case history below). However there are particular areas where non-ideal sequences are used, for example to save on access development, where rockburst resistant support may be an adequate risk mitigator. Some of the mines' faulted areas can be ideally sequenced and still be high risk for bursting. A combination of modified conebolts (yielding rockbolts) and mesh strapping is used over standard development support as the main burst resistant support package. Experience from other Canadian Mines (Falmagne and Simser, 2004) has shown this to be an effective measure.
The use of yielding cables (Strandlok) has been successful (see Onaping case study), and plans are to use debonded cables for deeper anchorage around faulted areas similar to use at the Hemlo Mining Camp (Bawden and Jones, 2002).

A common observation after bursting is that many of the bolts remain in the wall, with just the plate torn off or deformed. Adequate retainment, to transfer load to the tendons can be as important as the characteristics of the tendon itself, particularly when brittle rock shatters outward during a rockburst. Mesh strapping is used at Craig/Onaping to ensure effective load transfer to the plated bolt, and to connect adjacent bolts together creating a support system. The straps are $100 \times 100 \mathrm{~mm}$ weld mesh squares, $0.3 \mathrm{~m}$ wide, and either 2.1 or $3 \mathrm{~m}$ long with wire strand diameter of $7.7 \mathrm{~mm}$.

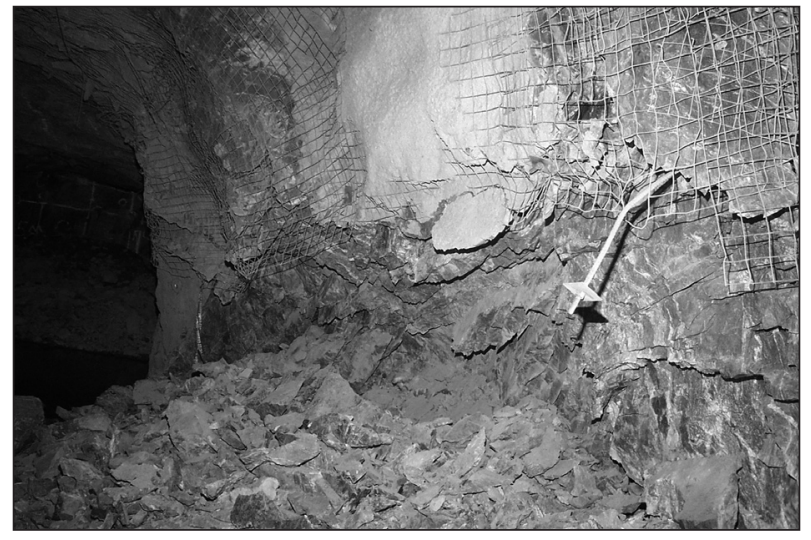

FIG. 1 Development wall burst triggered by a Nutli Magnitude 2.1 event locating $40 \mathrm{~m}$ away. Most of the damage was below the wall support line, but a rebar can be seen dangling. The brittle rock "shattered" out around the bar, never soliciting its' full strength

The difference between strain bursting and rock bursting is somewhat subjective, for the purposes of this paper, conventional tendons (e.g. rebar, mechanically anchored bolts) and weld mesh screen can contain a strain burst but not a rockburst. Fine loose caught in weld mesh screen is a common observation, although it is not always possible to distinguish between materials that "burst" into the support versus spalling in jointed material that creates small rock fragments. Increased screen bagging is often observed after moderate to large magnitude events.

The biggest risk for strain bursting is generally in development in the unsupported face area. Destress blasting (O'Donnell, 2001) is often used in development where four corner holes and sometimes a central blasthole are shot with the round. The toes of the holes are fired with ANFO ahead of the planned break to "push" the high stress front a bit further away from the face area.

A problem area continues to be below the wall support line. Scooptrams or roadway grading often rips out wall support, particularly below $1.5 \mathrm{~m}$ from the floor. End anchored bolts such as the modified conebolt, or mechanically anchored bolts become useless when the plate connection is lost. Equipment damage or rocks unravelling below the plate are the most common causes. This can be mitigated with shotcrete over the support, but this complicates support logistics and increases cost. Another problem lies with the ability of the mines' mechanized bolters supporting below about $1 \mathrm{~m}$ from the floor. Handheld equipment can overcome this problem; however the need has to be balanced with the exposure of the worker trying to install the support. 
In higher risk areas the development face is bolted and screened using SS46 splitsets installed by the drill jumbo. Mechanized bolters are almost exclusively used so that the worker is a safer distance away from the hazard.

Current research at Falconbridge Sudbury operations utilizing water scaling and thin spray-on liners is aimed at eliminating some of these difficulties. Thin spray-on liners can have the required resiliency to effectively contain strain bursting, and they can easily achieve close to $100 \%$ areal coverage (Archibald, 2004).

\section{SEISMIC MONITORING}

Both the Onaping and Craig Mines have dense uniaxial accelerometer arrays supplemented by three remote (2 surface and one underground) triaxial geophones. Location accuracies are typically within $10 \mathrm{~m}$, with some fall off at the array peripheries. Large events are quantified using the geophone stations, as the dynamic range of the uniaxial hardware/software combination is limited and the surface sites provide a far field observation point. Accurate locations are provided by the underground arrays, but sensor saturation and low frequency limitations prevent accurate source parameter estimates above about moment magnitude 0 .

Craig - 9505 March 19 to 31

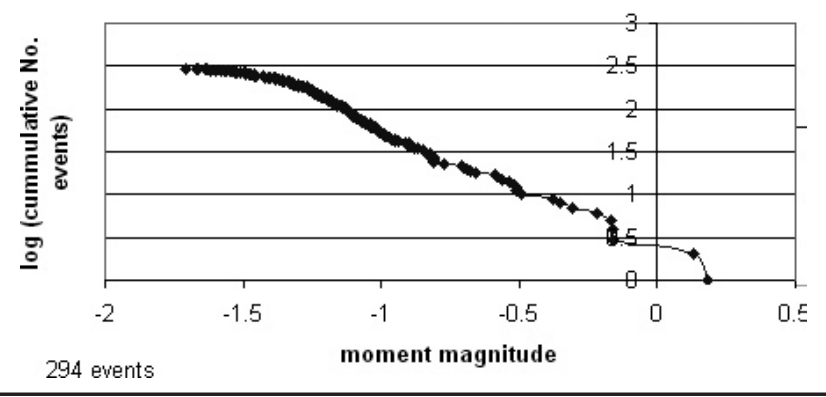

FIG. 2 Typical Gutenberg-Richter plot for Craig Mine. In this case the data is from a sill pillar recovery (see case histories below)

The Craig mine array has 80 -channel capacity with 50 active channels. The Onaping array is covering the lower portion of the mine only (not the historically mined out areas) with 32 channel capacity and 15 operating channels. Both arrays are incrementally expanded each year as mining progresses.

Emphasis is still placed on seismic activity rates for proactive work place closures and re-entry protocols (independent of source parameters). Seismic stress indicators are sometimes used to evaluate risk in different areas (as per Simser and Falmagne, 2004). The Onaping array currently has limited sensors, limiting the reliability of source parameter estimates, although this short-coming will be removed after array expansion.

\section{CASE HISTORIES}

\subsection{Onaping Mine Case Study}

The Onaping Mine is located about $1 \mathrm{~km}$ northwest of Craig Mine and mining is gradually extending to depth with current development down to $1740 \mathrm{~m}$ below surface. Ore and material are transported via truck from a lateral drive/ramp system from Craig Mine at the $1500 \mathrm{~m}$ elevation. Figure 3 below shows the overall relationship between the current mining at Craig/Onaping and the known mineral resources at depth.

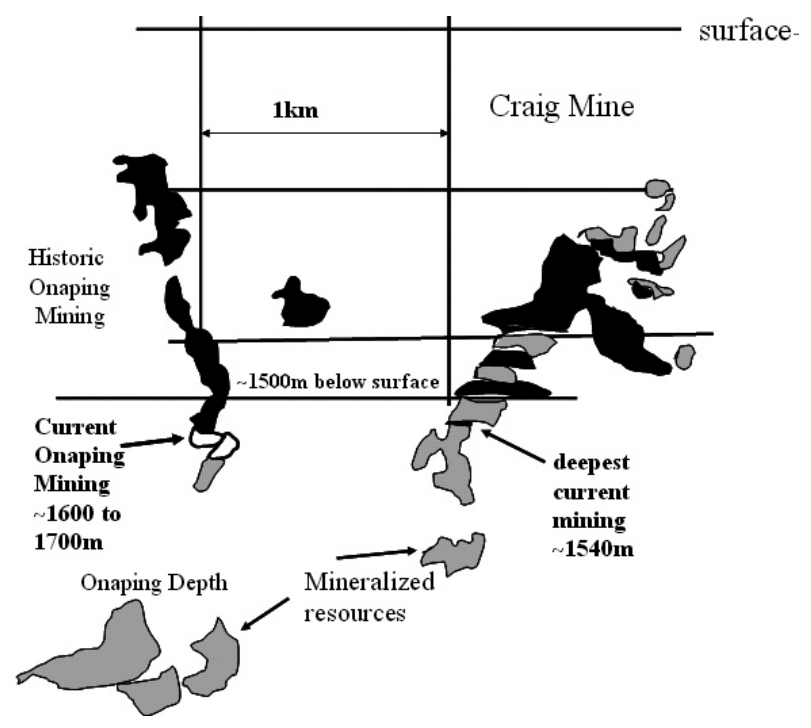

FIG. 3 Simplified Longitudinal Section of the Craig/Onaping Nickel Mining Complex

The current stoping at Onaping is by blasthole methods with the 53-900 stope being a conversion from post pillar cut and fill mining. This stoping block has two 20 vertical metre mining blocks divided into panels. The bottom undercut and the intermediate sub-level were mined using post pillar cut and fill methods. The upper $20 \mathrm{~m}$ section is being mined using a footwall drill drift and fan-hole drilling, while the bulk of the lower $20 \mathrm{~m}$ was mined using conventional blasthole with near vertical down holes from within the stope. A major problem with the area was that the intermediate level had been excavated up to $40 \mathrm{~m}$ wide with only $5 \times 5 \mathrm{~m}$ post pillars to break the span. Changes in the mining plan had left this area open for several years. The planned fan-hole portion was up to $25 \mathrm{~m}$ wide, leaving a low grade hangingwall lens behind.

A numerical modelling exercise was conducted by Itasca Canada (O'Connor et al., 2004) using 3DEC. The three-dimensional inelastic code was used to optimise the placement of the fan drill drift and to evaluate mining sequence options. An Isometric view of the model is shown in Figure 4, with the undercut labelled 54-975 and the overcut 53-900. The orebody extension at depth is labelled 55 and 56 level respectively (5500 feet or $1676 \mathrm{~m}$ below surface).

The modelling results clearly high-lighted some of the potential problems or high risk areas for the mining plan:

- The fan hole drill drift would have to be located in highly stressed brittle rock (granitic units, mainly felsic gneiss) in order to maintain practical drilling lengths/angles.

- The wide span portion of the high grade ore had extensive failed ground above the intermediate sub-level (later verified by visual examination after first fan-hole panel was mined).

- A granitic waste pillar occurred on the east abutment of the uppers stope which due to geometry and rock strength was not expected to fail, but to store very high stresses.

- The narrow tail of the orebody on the western side was not expected to fail because of the "squat" geometry, and was expected to carry very high stresses.

Historical experience suggested that both the narrow portion of the ore zone and in particular the granitic waste pillar could potentially yield large seismic events. 


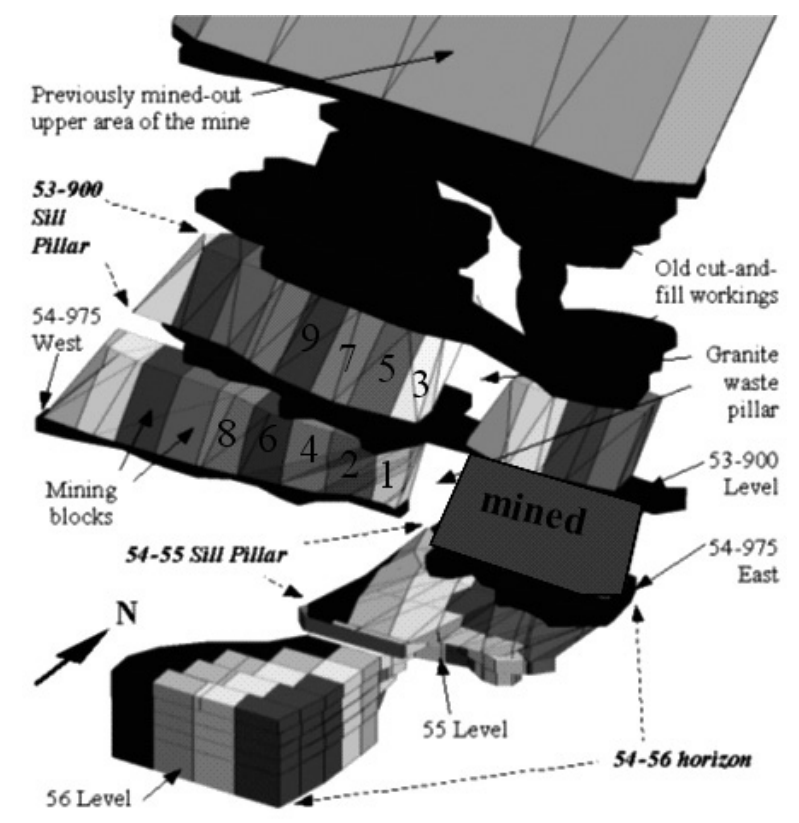

FIG. 4 Isometric view of the 53-900 sill pillar recovery at Onaping Mine (O'Connor et al., 2004)

The initial blasthole stopes were mined down using conventional in the stope drilling. Extra ground support measures (extendable super-swellex bolts, shotcrete pillars, and heavily supported post pillars) were used to ensure worker safety, but it was felt that re-entry to drill up-holes after backfilling the lower portion would be too high a risk. The post pillars from the cut and fill mining were supported with "Strandlok" cables (Ground Control (Sudbury) LTD) and heavy gauge mesh straps (plus shotcrete in some cases). The cables are installed with resin, using the cable bulges as the mixing mechanism, spinning on insertion. The head of the cable has a yielding swage, which was set at 15 tonnes, while the cable itself is a conventional 7 strand with $\sim 28$ tonne capacity. The sliding mechanism at the cable collar can absorb in the neighbourhood of $5 \mathrm{~kJ}$ of dynamic energy (Simser, 2003) and dampens the peak load if hit in impact. It is designed more for slow yielding, where surface bulking can be controlled somewhat without putting high loads on the cable. Figure 5 shows a close-up photo of a cable installed over a 00 gauge mesh strap in a $5 \times 5 \mathrm{~m}$ post pillar. The support system included conventional weldmesh, rockbolts and rebar. The pillars were observed to be bulking/yielding but were kept from un-ravelling to preserve their residual strength.

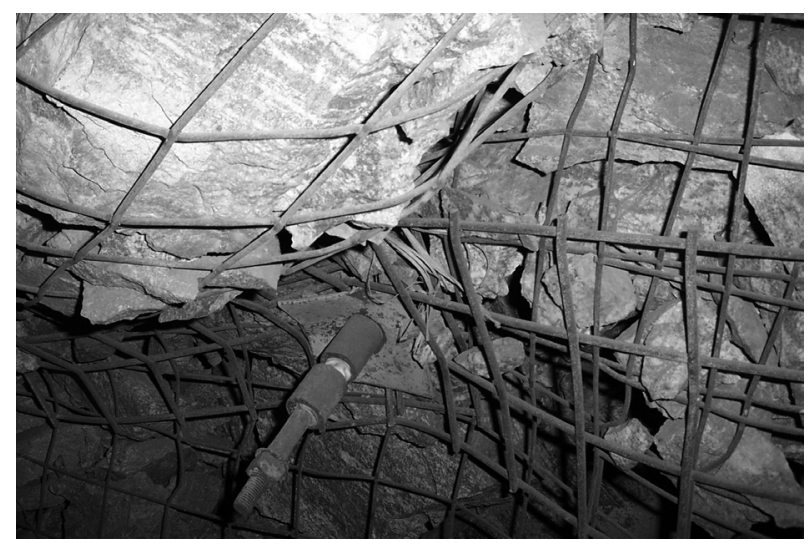

FIG. 5 Close-up photo of "Strandlok" cable after swage (sliding mechanism next to plate) has yielded close to $100 \mathrm{~mm}$
At the time of writing three downhole panels and two fan-hole uppers panels had been successfully extracted. The fan-hole drill drift was heavily supported with modified conebolts and straps overtop of the standard development support (mix of rebar, rockbolts, and No.7 gauge screen). Shotcrete was used for the drill hole wall to reduce the effects of blasthole "rifling". Due to production constraints, one area did not get shotcreted in time, and the blasting did cause significant damage to the wall support (proper stemming and accurate drilling can also dramatically reduce this problem). Approximately $2 \mathrm{~m}$ of stress fracturing was observed in the back, and in one small area had to be scaled down and rehabilitated. The walls had about $1 \mathrm{~m}$ of intensely fractured material, and severe drill hole squeezing was noted after blasting. Although no rock bursts were observed, the ground support system was successful at controlling bulking, strain bursting, and heavy blast vibrations.

The second fan-hole panel was planned to be mined by incrementally firing vertical slices into the first panel due to difficulties with backfilling. Safe locations for fill fences meant that the fan-hole panels would have to be filled with some fill migrating to a future undercut area. The difficulty handling waste at the remote Onaping location, meant that mucking out and rehandling backfill would be a major expense. Only two drill rings were fired, and approximately two thirds of the stope came down (6700 tonnes planned, 13200 tonnes actual). The non-entry mining method allowed for safe extraction of the material, with remote drilling of oversize required. This blasting induced failure was consistent with the stress model predictions (volume of failed ground collapsed) and verified the premise of the initial design (i.e. extra cost of a heavily supported drill drift, longer drill holes, and non-entry requirement).

The narrow portion of the orebody, panels 8,9 and the unlabelled blocks to the left in Figure 4 is expected to be higher risk but contains a relatively small proportion of the contained metal. Conceptual plans are to use tunnels through cemented fill and fan-hole drilling for recovery.

\subsection{Sill Pillar Recovery, Coming Under Cemented Fill}

Cut and fill horizons at Craig Mine are typically mined in $5 \mathrm{~m}$ vertical slices up to within $20 \mathrm{~m}$ of the next sill. When a quality sill matt is emplaced, the strategy is normally to drive under the backfill, with rock walls and floor. This creates an overcut in stress fractured ground with low stress backfill above (i.e. low burst potential). The sill mats are reinforced with either gabion weld mesh screen baskets or rebar plated on both ends with screen attached to the bottom double plate. Blasthole methods are employed to recover the sill using the last cut and fill horizon as the undercut. Given that sill recoveries are generally highly stressed, the goal is to ensure workers can operate in a safe location, either via remote control mucking from the undercut or under the stress shadow of the over-lying cut and fill horizon.

Mining widths under the sillmat are kept to a minimum, and fanhole recovery is used for stope blasting. If the sillmat gets damaged during development, splitsets and screen are used for repair. Generally the splitsets are drilled about $1 /{ }_{3}$ to $1 / 2$ their length, and then driven in the remainder of the way to improve their pullout strength in fill (the drilling process can create larger than desired hole sizes, the more the bolt can be driven in, the better). Several sill pillars have been successfully recovered at Falconbridge Sudbury operations by mining under sill mats. 


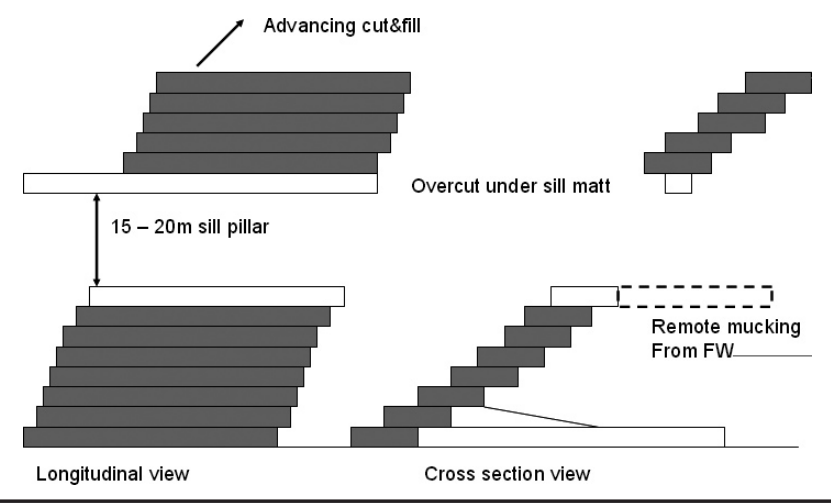

FIG. 6 Schematic of typical Craig Mine cut \& fill layout

\subsection{Sill Pillar Recovery, 9505 Stope}

The 9505 sill pillar is being recovered using blasthole uppers because of quality problems with the cement backfill in the sill mat above. The ore zone width varies from 5 to $35 \mathrm{~m}$, with the wider areas consisting of mostly massive sulphides, and the narrower areas a lower grade disseminated sulphide ore. The contrast between the stiffer low grade areas (both geology and geometry contributing to the stiffness difference) and the softer high grade area can be shown with a seismic event plot as per Figure 8. Figure 7 below shows the general layout of the area. The seismicity occurs predominantly in the footwall of the orebody (top of Figure 7) and a higher event density occurs by the narrow end of the lens (stiffer material).

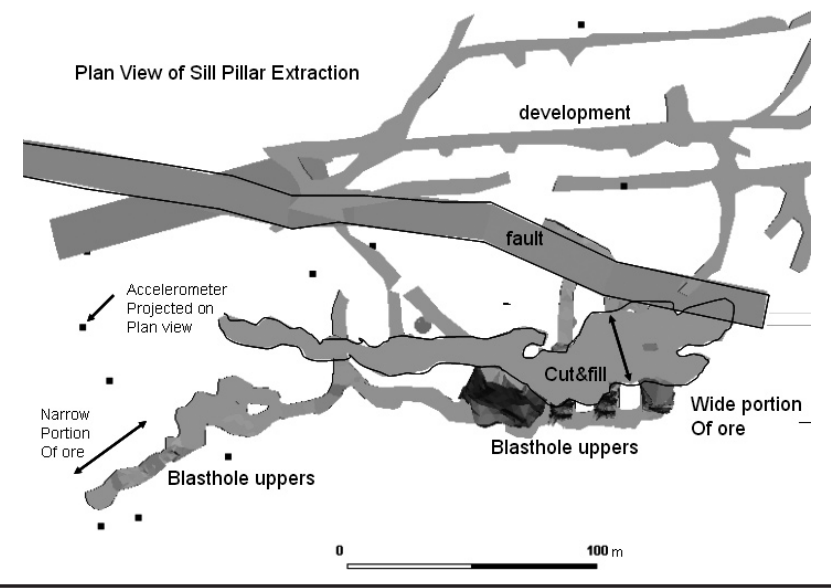

FIG. 7 General layout for the 9505 stope sill recovery

The progressive cuts below the blasthole undercut and above the sill pillar are not shown for clarity. The wider portion of the orebody was mined using primary/secondary stopes. Leaving pillars in high stress situations must be carefully considered, but if the pillar is designed to fail, then it can be mined in a residual stress state with low rock burst potential.

Mining in failed ground has inherent difficulties, with a higher fall of ground potential, and more difficult blasthole drilling however these are lesser "evils" relative to unpredictable bursting. For the two secondary pillars in the 9505 sequence the following measures were used to reduce risk: a rib of ore was left until final blasting so that the dead weight of the pillar above could be supported (particularly important after the slot blast removes clamping stresses); shotcrete in the development to help keep the fractured rock together and reduce the risk of blasthole drilling disturbing the near surface rock; swellex bolting was required due to difficulties using resin or grouting in fractured ground; and development spans were kept to a practical minimum.

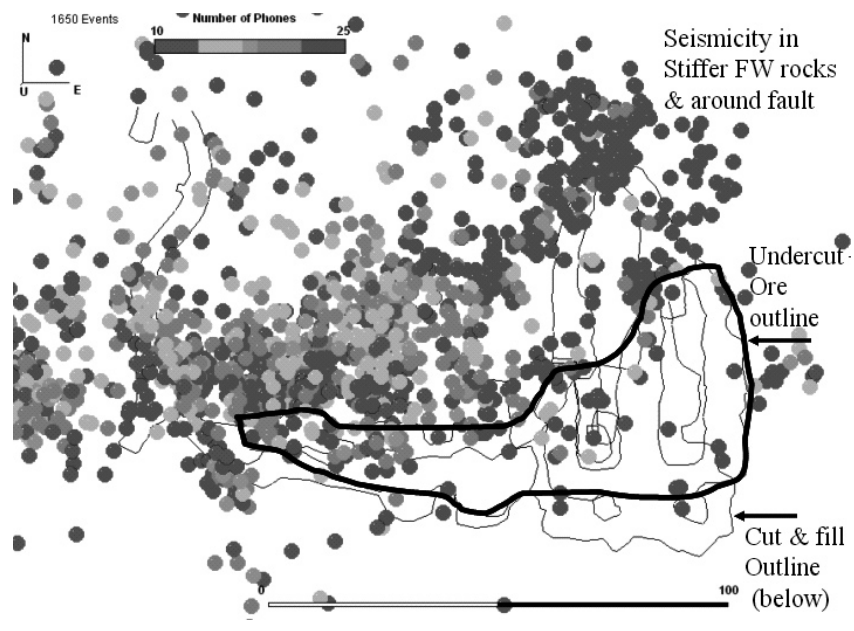

FIG. 8 Seismicity in the sill pillar area from June 2003 to July 2004. Six out of a total of ten panels had been mined at this stage. Note the activity is almost exclusively on the footwall side, and more towards the narrow tail of the ore despite lower volumetric extraction versus the wider portion

Detailed design work can be used to ensure the pillars will fail, avoiding the worst-case scenario of mining "failing" pillars. For high stress situations a simple rule of thumb is to keep the width to height ratio of the pillar less than $2 / 3$ (Lunder 1994) where the height is the dimension parallel to the principal loading direction. For the wider portion of the orebody ratios of $2 / 7$ and $2 / 5$ were used for the secondary pillars, generally to fit with the cut and fill post pillar pattern and convenient development. For the narrower portions, a retreat advance was used as leaving pillars would have likely resulted in highly stressed ground due to their squat dimensions. An overall centre out mining sequence was used to prevent trapping high stresses in a diminishing pillar. Previous experience in some Falconbridge Sudbury operations, including Craig Mine has shown that large magnitude seismicity can be generated in sill recoveries (Blake and Hedley, 2001); particularly if a non-ideal rock mechanics sequence is used.

\subsection{0/11 Zone}

The current deepest mining at Craig Mine is called 10-zone, with the down dip extension referred to as 11-zone. In April 2003 there were two violent ejection type rock bursts, one in the first cut of a 10-zone post pillar stope, the other near the bottom of the mine (development for 11-zone). No injuries occurred, but both locations were accessible to workers.

The sill cut burst was triggered by a fault slip event approximately $45 \mathrm{~m}$ from the damage location (event's epicentre as located by the seismic array was $45 \mathrm{~m}$ from damage). A Nutli magnitude 3.0 event triggered a violent ejection type burst in a PYHF inclusion of several metres in extent. The damage was interpreted as being caused by 1) the large event triggering local rock bursts, 2) and by violent seismic shaking of heavily structured areas, particularly the main intersection (wider span) in which the main fault daylighted. In all, three different portions of the back collapsed, being separated by heavily shattered rock. The burst damage was later intersected on the next cut, which had been switched to a drift and fill mining method to limit spans. Increased use of rockburst support (modified conebolts and straps) as well as long tendons ( $3.5 \mathrm{~m}$ or greater) were also used on the subsequent cut. In all an estimated 4000 tonnes of material was dislodged. 
Two weeks later a Nutli Magnitude 2.1 event on a different portion of the fault zone triggered a wall burst in the down ramp development (see Figure 1 above). Mining was halted after the first burst, and a revised mining plan was made. Geotechnical drilling was conducted to refine geological information for 11-zone. More accurate fault locations, core discing, and fracture frequency were determined. An anomalously high zone of core discing was found in the footwall of the 11-zone mineralization. The conventional footwall access was replanned in favour of an end access to the ore lens. The footwall accesses would have traversed through the inferred high stress area (based on core discing), through stiff granitic rocks (burst prone material), and through the major fault zone. Although a less flexible mining sequence and more development resulted in the end access, the development could be kept in either the "softer" ore zone, or in the more jointed hangingwall rocks, and outside the inferred stress anomaly.

The remaining portion of 10-zone and the top $100 \mathrm{~m}$ of 11-zone was converted to blasthole stoping as steep enough dips and relatively persistent mineralization was postulated from the geological information. The advantage of blasthole versus cut and fill was: lower mining costs (important given that both zones have modest nickel grades $<2 \%$ ); non-entry mining methods could be used; overcuts could be made underneath cemented backfill (sill mats); and less development allowed more use of costly burst-prone support systems. A serious disadvantage is that larger stress changes from blasthole stoping would likely cause more severe stress changes (e.g. increased shear stress or larger loss of clamping stress) on the fault system.

Experience in the cut and fill mining through the same fault zone has shown the large seismic events occasionally occur, despite small incremental stress changes (typically 500 tonne blasts). The predictability of large events remains difficult at best, with some of them occurring without seismic precursors (Figure 9), and others with an increased event rate. Pro-active closures of working areas is done when an anomalously high event rate occurs, but it is recognized that this is still somewhat subjective and is not fool proof.

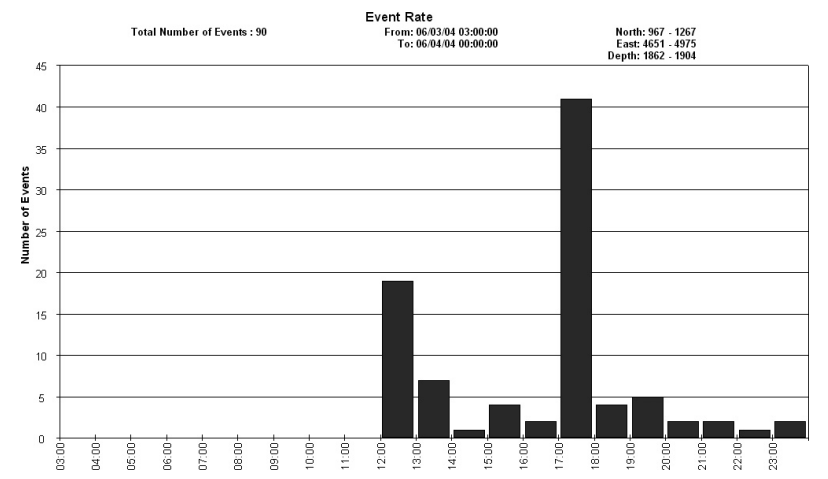

FIG. 9 Event rate plot for lower 10-zone seismic activity on June 3,2004 . Overbreak occurred in a vent raise bracketed by the main fault system. The First event in the sequence was a Nutli Magnitude 1.9, and the first event in the second peak of activity was a Nutli Magnitude 2.5, in both cases the microseismic activity rate did not offer a forewarning

Rockburst support is planned around the intersection of the major faults in the zone, typically $+/-7 \mathrm{~m}$ from the fault. A difficulty in predicting the local fault behaviour is the variation in the amount of fault gouge present. In some areas up to $1 \mathrm{~m}$ of gouge occurs, creating a weak zone and potential wedge failures and/or deformation driven failure. Generally speaking there is a high wedge failure potential where the moderately dipping faults (typically $30^{\circ}$ ) come over the back of an excavation. Super-swellex bolts or cablebolts are used to tie blocks into more solid ground in addition to the burstprone support. Where possible the faults are traversed at $90^{\circ}$ (shortest distance across) and intersections in immediate fault influence are avoided.

\section{CONCLUSIONS}

Rockburst risk can be kept at manageable levels with proper rock mechanics strategies. At Craig/Onaping Mines a combination of tactical and ground support strategies are used for risk mitigation. In some areas, particularly the lower portion of Craig Mine which traverses a major fault zone, some worker exposure exists despite best efforts of sequencing and remote access. Yielding support such as modified conebolts and mesh strapping is used in high risk areas.

Where possible a tactical solution is preferred, such as creating an overcut under cemented backfill. Stress fracturing around the historic excavations, and stress shadowing make this type of access a low rockburst risk.

Knowledge of geology and local ground conditions is the key to understanding rockburst risk, and the influence of mining on how that risk changes. It is possible to rate different areas in the mine and target only the exceptions for more expensive support and mining strategies.

\section{ACKNOWLEDGMENTS}

The Author would like to thank Management of Falconbridge Sudbury Operations for permission to publish this paper, and to the ground control staff that have developed many of the strategies currently used on a routine basis (Graham Swan, Scott Carlisle, Chris Pritchard, Rick Deredin and others).

\section{REFERENCES}

Archibald, J.F. (2004) Comparative Evaluation of Area Support Systems for Rockburst Damage Mitigation. 19th Colloque de Controle de Terrain. Association miniere du Quebec. March 16, 2004. Val D'or, Quebec, Canada.

Bawden, W.F. and Jones S. (2002) Ground support design and performance under strong rockburst conditions. In Proceedings of the 5th North American Rock Mechanics Symposium, Toronto, 07-10 July 2002 (eds. R. Hammah, W.F. Bawden, J. Curran, M. Telesnicki) University of Toronto Press, Canada, pp. 923-931

Blake, W. and Hedley D.G.F. (2001) Rockburst Case Histories for North American Hardrock Mines. Industry sponsored research report. CAMIRO Mining Division, 933 Ramsey Lake Road, Sudbury, Ontario, Canada.

Falmagne, V. and Simser, B.P. (2004) Performance of Rockburst Support Systems in Canadian Mines. In Proceedings of the 5th International Symposium on Ground Support in Mining and Underground Construction. Perth, Australia, 28-30 Sept. 2004.

Ground Control (Sudbury) LTD. Ground Support Supplier. http:/ / cybersudbury.com/hosts/groundcontrol/

Hoek, E. (2000) Practical Rock Engineering. Reference notes available by free download. www.rocscience.com/hoek/PracticalRockEngineering.asp

Lunder, P. (1994) Hard rock pillar strength estimation: an applied empirical approach. M.Sc. Thesis. University of British Columbia.

O'Connor, C.P., Andrieux, P., Pritchard C. and Simser, B.P. (2004) Numerical Modelling With 3DEC and Risk Assessment for a Geometrically Complex and Highly Stressed Sill Pillar at Onaping Mine. In Proceedings of 1st International Symposium on UDEC/3DEC. Bochum, Germany. Sept. 2004.

O'Donnell Sr., D.P. (2001) Destressing Drifts to Regional Pillars to Reduce the Risk of Rockbursts. Canadian Institute of Mining. 15th Mine Operator's Conference, February 11-15, 2001, Sudbury, Ontario, Canada.

Simser, B. and Falmagne, V. (2004) Seismic source parameters used to monitor rockmass response at Brunswick Mine. Canadian Institute of Mining Bulletin. May 2004, pp. 58-63.

Simser, B. (2003) Dynamic testing of "Strandlok" cables. Noranda Technology Centre, internal report, April 2003. 